ORIGINAL ARTICLE

\title{
Cardiorespiratory fitness and risk of disability pension: a prospective population based study in Finnish men
}

\author{
M Karpansalo, T A Lakka, P Manninen, J Kauhanen, R Rauramaa, J T Salonen
}

Occup Environ Med 2003;60:765-769

See end of article for authors' affiliations

Correspondence to:

Dr M Karpansalo,

Research Institute of Public

Health, University of

Kuopio, PO Box 1627

70211 Kuopio, Finland;

minna.karpansalo@

medivire.fi

Accepted

7 November 2002
Background: Early retiring is a major social problem in many western countries.

Aim: To investigate whether good cardiorespiratory fitness prevents disability pensioning in Finnish middle-aged men.

Methods: Subjects were a random population based sample of 1307 men who were $42-60$ years old at baseline, had not retired before baseline or died during follow up, and had undergone a cycle ergometer test at baseline. Cardiorespiratory fitness was assessed at baseline with a maximal but symptom limited exercise test on an electrically braked cycle ergometer.

Results: During a follow up of 11 years on average, 790 (60.4\%) men were awarded a disability pension, only 254 (19.4\%) men reached the old-age pension without previous early pension, and $263(20.1 \%)$ men were still working at the end of follow up. After adjustment for age, body mass index, alcohol consumption, smoking, education, occupation, and baseline chronic diseases, an inverse association was observed between cardiorespiratory fitness and the risk of disability pension. Men with $\mathrm{VO}_{2 \max }$ $<25.98 \mathrm{ml} / \mathrm{kg} / \mathrm{min}$ (lowest fifth) had a 3.28 -fold $(95 \% \mathrm{Cl} 1.70$ to 6.32 ) and men with the duration of exercise test $<9.54$ minutes (lowest fifth) had a 4.66 -fold $(95 \% \mathrm{Cl} 2.43$ to 8.92 ) risk of disability pension due to cardiovascular diseases compared with men in the highest fifths. Men with lowest fitness level also had an increased risk of disability pension due to musculoskeletal disorders, or all reasons combined. Conclusions: Physical fitness is inversely associated with the risk of disability pension and especially with the risk of disability due to cardiovascular diseases.
E arly retiring is a major social problem in many western countries; the situation will be worse in the near future as the mean age of the working population is increasing. Thus, there is a need to find strategies to prevent disability and to maintain working ability. Although disability pension is awarded due to a chronic disease, many other factors such as legislation, social and labour policy, work history, and individual factors intervene. ${ }^{1-4}$ In many epidemiological studies non-medical factors have been even more important predictors of disability than medical ones. ${ }^{5-9}$ However, few earlier studies have been longitudinal, and in few of them has disability been measured by awarded pensions. ${ }^{50-13}$

For prevention of early retirement, more information is needed about the modifiable risk factors for disability. Physical inactivity and poor cardiorespiratory fitness are potentially important modifiable risk factors for disability. It has been estimated that only one third of adult Finns exercise enough to improve their health. ${ }^{14}$ Regular physical activity has a number of favourable cardiovascular, musculoskeletal, metabolic, hormonal, neurological, respiratory, and mental effects, and it delays many physical ageing processes and increases functional capacity. ${ }^{13}{ }^{15-19}$ Moreover, physical activity and good cardiorespiratory fitness have been associated with a reduced risk of cardiovascular diseases. ${ }^{15} 182021$ Of musculoskeletal diseases, physical activity or good physical fitness have been observed to prevent osteoporosis, ${ }^{22-24}$ and they may also reduce the risk of low back and neck-shoulder disorders. ${ }^{16} 192425$ In osteoarthritis high dose physical activity may promote the degeneration process of the injured joint, ${ }^{24} 26$ but at moderate level of activity the degeneration process of the joint may be prevented. ${ }^{28} 29$ Physical activity has been shown to be associated with reduced symptoms of depression, but the evidence is not strong. ${ }^{30}$

Although there is a considerable amount of evidence about the health effects of regular physical activity and good physical fitness, there are no previous prospective population based studies concerning the association between cardiorespiratory fitness and the risk of disability pension. We therefore investigated the associations of two measures of cardiorespiratory fitness, maximal oxygen uptake from respiratory gas exchange analysis and the duration of a cycle ergometer exercise stress test, with the risk of disability pensions due to cardiovascular, musculoskeletal, and mental causes, ascertained using pension registers that cover all Finnish citizens, in a representative population based sample of middle-aged men from eastern Finland.

\section{METHODS}

\section{Subjects}

Subjects were the participants of the Kuopio Ischaemic Heart Disease Risk Factor Study (KIHD), ${ }^{31}$ an ongoing population based study, the aim of which is to investigate risk factors for chronic diseases and related outcomes. The subjects are a randomly selected sample of men living in the town of Kuopio or surrounding rural communities in eastern Finland. The men were $42,48,54$, or 60 years old at baseline examinations between March 1984 and December 1989. Of 3235 eligible men, $2682(82.9 \%)$ participated. Men who had retired before the baseline $(\mathrm{n}=898)$, had a non-illness based pension $(\mathrm{n}=331)$, had died during follow up $(n=29)$, or did not do the cycle ergometer test $(\mathrm{n}=117)$ were excluded. Thus, the final study population included 1307 men, of whom 94.3\% ( $\mathrm{n}=1233)$ were full time workers, $1.6 \%(n=20)$ were part time workers, $3.2 \%$ $(\mathrm{n}=42)$ were unemployed, and $0.9 \%(\mathrm{n}=12)$ were laidoff from work at baseline.

\section{Assessment of cardiorespiratory fitness}

Cardiorespiratory fitness was assessed at baseline between August 1986 and December 1989 with a maximal but 
Main messages

- Early retiring is a significant social problem in western countries.

- Methods to prevent early retiring and to maintain working ability are needed.

- More prospective studies are needed to investigate the effect of physical activity, cardiorespiratory fitness, and exercise intervention programmes in the prevention of early retiring.

- In the present study even moderate levels of physical fitness were associated with a decreased risk of disability pension; this was most clearly seen in cardiovascular diseases.

symptom limited exercise test on an electrically braked cycle ergometer, as explained in detail previously. ${ }^{15}$ For 318 $(24.3 \%)$ men who were examined before June 1986, the testing protocol comprised a three minute warm up at $50 \mathrm{~W}$ followed by a step by step increase in the workload of $20 \mathrm{~W}$ per minute. The remaining $989(75.7 \%)$ men were tested with a linear increase in the workload of $20 \mathrm{~W}$ per minute. ${ }^{18}$ The electrocardiogram (ECG) was registered continuously during the exercise stress test. The exercise tests were supervised by an experienced physician and assisted by an experienced nurse to obtain reliable information about exercise test variables, and also for safety reasons. The exercise tests were performed between 8 and 10 am. Oxygen consumption was measured using respiratory gas exchange analysis. The maximal oxygen uptake $\left(\mathrm{VO}_{2 \max }\right)$ was defined as the highest value for or the plateau in oxygen uptake and was indexed by body weight (in $\mathrm{ml} / \mathrm{kg} / \mathrm{min}$ ). The duration of exercise test was used as another measure of cardiorespiratory fitness.

\section{Measurement of early retirement}

The cohort was linked to the pension registers of the Social Insurance Institution, the Central Pension Security Institute, and some smaller pension institutions covering all the pensions of these subjects from baseline until 31 May 2000. The Social Insurance Institution is responsible for the basic social security provision for disability of every Finnish citizen from the age of 16 to 65 years. The Central Pension Security Institute is the statutory central body of the private sector pension institutions.

In Finland, when a person becomes ill and the illness causes a disability, the first step is to claim sickness allowance. The disability pension is applied if disability continues over 300 days. The individual early retirement pension is another form of a disability pension that can be applied if a person is at least 58 years old, she/he has some chronic disease reducing working capacity, and work history is long. Eligibility for both pensions requires a comprehensive medical certificate written by the attending physician and approved by an expert adviser on behalf of the Social Insurance Institution and the Central Pension Security Institute. The first diagnosis on the medical certificate made by an attending physician was regarded as the main cause of disability. In this study disability pension includes both the usual disability pensions and the individual early pensions.

\section{Assessment of other variables}

The assessment of occupation, education, ${ }^{32}$ smoking, ${ }^{33}$ body mass index, ${ }^{34}$ and alcohol consumption ${ }^{35}$ has been explained in detail previously. Chronic diseases diagnosed by a doctor were inquired in the questionnaire at baseline. The diseases
Policy implications

- More attention should be paid to improvement of cardiorespiratory fitness by physically active lifestyle in the working aged populations.

were classified as follows: (1) cardiovascular diseases (coronary heart disease, cardiac insufficiency, hypertension, claudication, stroke); (2) musculoskeletal disorders (back problems, osteoarthritis); (3) mental disorders; and (4) other chronic diseases.

\section{Statistical methods}

Statistical analyses were performed using SPSS 10.0 for Windows. The associations of $\mathrm{VO}_{2 \max }$ and the duration of exercise test with the risk of disability pension were analysed using logistic regression analysis. ${ }^{36} \mathrm{VO}_{2 \max }$ and the duration of exercise test were categorised into quintiles, and men in the highest quintile were used as a reference group. Age, education, occupation, body mass index, alcohol consumption, smoking, and corresponding baseline disease (cardiovascular, musculoskeletal, mental, or other disease) were used as potential confounders.

\section{RESULTS}

\section{Characteristics of the subjects}

Table 1 shows characteristics of the subjects. Men who had been awarded disability pension had a lower $\mathrm{VO}_{2 \max }$ and a shorter duration of exercise test than men who were still working or had been at working life up to a normal old age pension. Moreover, they were older, smoked a little more, were less educated, were more likely blue collar workers, more likely had some cardiovascular disease or musculoskeletal or mental disorder, and had a slightly higher body mass index than the men in the reference group. Only $16.7 \%$ $(n=218)$ of the men did not have any chronic disease at baseline.

\section{Retirement during follow up}

Of 1307 men, $790(60.4 \%)$ were awarded a disability pension during follow up, $254(19.4 \%)$ retired at the normal pensionable age of 65 years, and 263 (20.1\%) were still working at the end of follow up. The main medical diagnoses for disability were musculoskeletal disorders $(\mathrm{n}=310$, $39.2 \%)$, cardiovascular diseases $(\mathrm{n}=226,28.6 \%)$, and mental disorders $(\mathrm{n}=108,13.7 \%)$ (table 1$)$.

\section{Cardiorespiratory fitness and other characteristics}

$\mathrm{VO}_{2 \max }$ had a strong inverse association with age, body mass index, smoking, and the prevalence of cardiovascular diseases at baseline (table 2). Moreover, the subjects with a low $\mathrm{VO}_{2 \max }$ were less likely to have a high school or middle school education than those with a high $\mathrm{VO}_{2 \max }$ The duration of exercise test was correspondingly inversely associated with age, smoking and the prevalence of cardiovascular diseases (data not shown).

\section{Cardiorespiratory fitness and the risk of disability pension}

After adjustment for age, education, occupation, alcohol consumption, smoking, and prevalent diseases at baseline, $\mathrm{VO}_{2 \max }$ and the duration of exercise test had an inverse association with the risk of all disability pensions combined (table 3). Lower $\mathrm{VO}_{2 \max }$ and shorter duration of exercise test was most strongly associated with the risk of disability due to cardiovascular diseases (odds ratio 3.58, 95\% confidence 
Table 1 Characteristics of the subjects

\begin{tabular}{|c|c|c|c|c|}
\hline & $\begin{array}{l}\text { All subjects } \\
\text { ( } n=1307)\end{array}$ & $\begin{array}{l}\text { Disability retirees } \\
(\mathrm{n}=790)\end{array}$ & $\begin{array}{l}\text { Working men/old age } \\
\text { retirees }(n=517)\end{array}$ & $\begin{array}{l}\text { p value for difference } \\
\text { between groups }\end{array}$ \\
\hline Age (years) & $51.3(5.2)$ & $52.5(4.0)$ & $49.4(6.2)$ & $<0.001$ \\
\hline Body mass index $\left(\mathrm{kg} / \mathrm{m}^{2}\right)$ & $26.7(3.4)$ & $26.9(3.5)$ & $26.5(3.1)$ & 0.022 \\
\hline Alcohol consumption (g/week) & $74.2(110.4)$ & $74.4(113.6)$ & $74.0(105.5)$ & 0.948 \\
\hline Smoking (cigarettes/day) & $5.5(10.0)$ & $5.6(9.9)$ & $5.2(10.0)$ & 0.404 \\
\hline Maximal oxygen uptake $(\mathrm{ml} / \mathrm{kg} / \mathrm{min})$ & $31.8(7.5)$ & $30.3(7.3)$ & $34.0(7.4)$ & $<0.001$ \\
\hline Duration of exercise test (min) & $11.5(2.5)$ & $11.0(2.4)$ & $12.4(2.4)$ & $<0.001$ \\
\hline \multicolumn{5}{|l|}{ Education } \\
\hline High school or above $(n=120)$ & $9.2 \%$ & $5.7 \%$ & $14.5 \%$ & $<0.000$ \\
\hline Middle school $(n=510)$ & $39.1 \%$ & $36.6 \%$ & $42.8 \%$ & \\
\hline Elementary school or less $(n=676)$ & $51.8 \%$ & $57.7 \%$ & $42.6 \%$ & \\
\hline \multicolumn{5}{|l|}{ Occupation } \\
\hline Farmer $(n=225)$ & $17.5 \%$ & $19.1 \%$ & $15,1 \%$ & $<0.001$ \\
\hline Blue collar worker $(n=467)$ & $36.3 \%$ & $39.7 \%$ & $31,2 \%$ & \\
\hline White collar worker ( $n=593$ ) & $46.1 \%$ & $41.2 \%$ & $53,6 \%$ & \\
\hline \multicolumn{5}{|l|}{ Diseases/disorders at baseline } \\
\hline Cardiovascular diseases ${ }^{*}(n=653)$ & $50.0 \%$ & $58.1 \%$ & $37.5 \%$ & $<0.001$ \\
\hline Musculoskeletal disorderst $(n=566)$ & $43.3 \%$ & $49.1 \%$ & $34.4 \%$ & $<0.001$ \\
\hline Mental disorders $\ddagger(n=49)$ & $3.7 \%$ & $4.3 \%$ & $2.9 \%$ & 0.192 \\
\hline Other chronic diseases $\S(n=431)$ & & & & $<0.001$ \\
\hline \multicolumn{5}{|l|}{ Reasons for disability pension } \\
\hline Any reason $(n=790)$ & $60.4 \%$ & $100 \%$ & $0.0 \%$ & \\
\hline Cardiovascular diseases $(n=219)$ & $16.8 \%$ & $27.7 \%$ & $0.0 \%$ & \\
\hline Musculoskeletal disorders $(n=312)$ & $23.9 \%$ & $39.5 \%$ & $0.0 \%$ & \\
\hline Mental disorders $(n=108)$ & $8.3 \%$ & $13.7 \%$ & $0.0 \%$ & \\
\hline Other reasons $(n=151)$ & $11.6 \%$ & $19.1 \%$ & $0.0 \%$ & \\
\hline
\end{tabular}

Values are either percentages or means (standard deviations)

*Cardiovascular diseases include coronary heart disease, cardiac insufficiency, hypertension, claudication and stroke.

†Musculoskeletal disorders include back problems and osteoarthritis.

$\ddagger$ Mental disorders include those diagnosed by doctor or severe psychic illnesses that required hospitalisation.

§Other chronic diseases include chronic bronchitis, bronchial asthma, farmer's lung or other pneumoconiosis, lung tuberculosis, diabetes, epilepsy, thyroid illnesses, liver or pancreatic diseases, cancer, and rheumatoid arthritis.

-Other reasons include respiratory, metabolic, dermatological, digestive tract, eye and ear diseases, injuries, cancers, malformations, and non-classifiable diseases.

interval 1.91 to 6.70 , and odds ratio $4.56,95 \%$ CI 2.40 to 8.65 , respectively). Poor cardiorespiratory fitness was also associated with an increased risk of disability pension due to musculoskeletal disorders, and also showed a weak inverse association with disability due to mental disorders (table 3).

Table 2 Characteristics of the subjects in the fifths of maximal oxygen uptake

\begin{tabular}{|c|c|c|c|c|c|c|}
\hline & \multicolumn{5}{|c|}{ Quintiles of maximal oxygen uptake $(\mathrm{ml} / \mathrm{kg} / \mathrm{min})$} & \multirow{2}{*}{$\begin{array}{l}\text { p value for difference } \\
\text { between groups }\end{array}$} \\
\hline & I (low) & II & III & IV & V (high) & \\
\hline Age (years) & $53.9(3.9)$ & $52.3(4.6)$ & $51.2(5.0)$ & $50.4(5.3)$ & $48.5(5.5)$ & $<0.001$ \\
\hline Body mass index $\left(\mathrm{kg} / \mathrm{m}^{2}\right)$ & $28.4(4.2)$ & $27.4(3.3)$ & $26.6(3.1)$ & $26.2(2.7)$ & $25.2(2.4)$ & $<0.001$ \\
\hline Alcohol consumption (g/week) & 79.8 (112.9) & $74.8(110.6)$ & $83.7(134.0)$ & $61.3(86.8)$ & $71.0(100.9)$ & 0.177 \\
\hline & \multicolumn{5}{|c|}{ Education } & $<0.001$ \\
\hline High school or above $(n=120)$ & $1.0 \%$ & $1.8 \%$ & $2.5 \%$ & $2.2 \%$ & $1.7 \%$ & 0.001 \\
\hline Middle school $(n=510)$ & $6.6 \%$ & $6.9 \%$ & $8.2 \%$ & $8.0 \%$ & $9.3 \%$ & \\
\hline Elementary school or less $(n=676)$ & $12.6 \%$ & $10.6 \%$ & $9.8 \%$ & $9.0 \%$ & $9.7 \%$ & \\
\hline \multicolumn{7}{|l|}{ Occupation } \\
\hline Farmer $(n=225)$ & $3.5 \%$ & $3.6 \%$ & $3.9 \%$ & $4.0 \%$ & $2.5 \%$ & 0.096 \\
\hline Blue collar worker $(n=467)$ & $8.0 \%$ & $7.2 \%$ & $6.4 \%$ & $6.1 \%$ & $8.6 \%$ & \\
\hline White collar worker $(n=593)$ & $8.9 \%$ & $8.6 \%$ & $9.9 \%$ & $9.1 \%$ & $9.7 \%$ & \\
\hline \multicolumn{7}{|l|}{ Diseases/disorders at baseline } \\
\hline Cardiovascular diseases* $(n=653)$ & $15.0 \%$ & $11.3 \%$ & $9.9 \%$ & $6.9 \%$ & $6.9 \%$ & $<0.001$ \\
\hline Musculoskeletal disorders $†(n=556)$ & $9.5 \%$ & $9.0 \%$ & $9.1 \%$ & $7.7 \%$ & $8.0 \%$ & 0.163 \\
\hline Mental disorders $\ddagger(n=49)$ & $0.7 \%$ & $1.2 \%$ & $0.8 \%$ & $0.4 \%$ & $0.7 \%$ & 0.138 \\
\hline Other chronic diseases $\S(n=431)$ & $8.0 \%$ & $7.0 \%$ & $6.4 \%$ & $5.8 \%$ & $5.7 \%$ & 0.017 \\
\hline \multicolumn{7}{|l|}{ Reasons for disability pension } \\
\hline Any reason $(n=790)$ & $15.2 \%$ & $12.9 \%$ & $12.6 \%$ & $10.7 \%$ & $9.0 \%$ & $<0.001$ \\
\hline Cardiovascular diseases $(n=219)$ & $6.4 \%$ & $3.4 \%$ & $2.9 \%$ & $2.5 \%$ & $2.1 \%$ & \\
\hline Musculoskeletal disorders $(n=312)$ & $5.0 \%$ & $5.4 \%$ & $5.7 \%$ & $4.4 \%$ & $3.4 \%$ & \\
\hline Mental disorders $(n=108)$ & $2.0 \%$ & $1.9 \%$ & $2.3 \%$ & $1.7 \%$ & $2.2 \%$ & \\
\hline Other reasons $(n=151)$ & $1.8 \%$ & $2.4 \%$ & $1.7 \%$ & $2.1 \%$ & $1.3 \%$ & \\
\hline
\end{tabular}

Values are either means (standard deviations) or percentages

*Cardiovascular diseases include coronary heart disease, cardiac insufficiency, hypertension, claudication, and stroke.

† Musculoskeletal disorders include back problems and osteoarthritis.

$\ddagger$ Mental disorders include those diagnosed by doctor or severe psychic illnesses that required hospitalisation.

$\S$ Other chronic diseases include chronic bronchitis, bronchial asthma, farmer's lung or other pneumoconiosis, lung tuberculosis, diabetes, epilepsy, thyroid illnesses, liver or pancreatic diseases, cancer, and rheumatoid arthritis.

- Other reasons include respiratory, metabolic, dermatological, digestive tract, eye and ear diseases, injuries, cancers, malformations, and non-classifiable diseases. 
Table 3 Adjusted relative risk (OR) of disability pension by disease category in fifths of maximal oxygen uptake and the duration of exercise test

\begin{tabular}{|c|c|c|c|c|c|}
\hline & $\begin{array}{l}\text { Any reason }(n=790) \\
\text { OR }(95 \% \mathrm{CI})\end{array}$ & $\begin{array}{l}\text { Cardiovascular } \\
\text { diseases* }(n=219) \\
\text { OR }(95 \% \mathrm{CI})\end{array}$ & $\begin{array}{l}\text { Musculoskeletal } \\
\text { disorders† }(n=312) \\
\text { OR }(95 \% \mathrm{CI})\end{array}$ & $\begin{array}{l}\text { Mental disorders } ¥ \\
\text { ( } n=108) \\
\text { OR }(95 \% \mathrm{Cl})\end{array}$ & $\begin{array}{l}\text { Other reasons } \S \\
(n=151) \\
\text { OR }(95 \% \mathrm{Cl})\end{array}$ \\
\hline \multicolumn{6}{|c|}{ Maximal oxygen uptake $(\mathrm{ml} / \mathrm{kg} / \mathrm{min})$} \\
\hline $7.38-25.67$ & $2.08(1.36-3.19)$ & $3.58(1.91-6.70)$ & $2.20(1.26-3.83)$ & $1.44(0.73-2.83)$ & $2.04(0.96-4.34)$ \\
\hline $25.68-29.47$ & $1.72(1.15-2.56)$ & $2.10(1.11-3.93)$ & $2.03(1.20-3.44)$ & $1.10(0.57-2.13)$ & $2.23(1.11-4.47)$ \\
\hline $29.48-33.10$ & $1.73(1.18-2.54)$ & $1.93(1.03-3.60)$ & $2.18(1.31-3.64)$ & $1.41(0.77-2.59)$ & $1.58(0.78-3.21)$ \\
\hline $33.11-37.61$ & $1.54(1.05-2.25)$ & $1.85(1.00-4.57)$ & $1.71(1.02-2.89)$ & $0.96(0.51-1.81)$ & $1.89(0.95-3.74)$ \\
\hline 37.62-65.40 (reference) & 1.0 & 1.0 & 1.0 & 1.0 & 1.0 \\
\hline \multicolumn{6}{|l|}{ Duration of exercise test (min) } \\
\hline $1.50-9.54$ & $2.33(1.50-3.61)$ & $4.56(2.40-8.65)$ & $1.98(1.12-3.48)$ & $2.29(1.12-4.70)$ & $2.07(1.01-4.24)$ \\
\hline $9.55-10.82$ & $1.54(1.04-2.30)$ & $2.14(1.13-4.06)$ & 1.71 (1.01-2.89) & $1.29(0.65-2.58)$ & $1.40(0.71-2.75)$ \\
\hline $10.83-12.06$ & 1.73 (1.18-2.51) & $2.43(1.31-4.48)$ & 1.96 (1.19-3.24) & 1.93 (1.05-3.56) & 0.95 (0.47-1.93) \\
\hline $12.07-13.49$ & $1.46(1.01-2.11)$ & 2.00 (1.07-3.74) & $1.44(0.86-2.41)$ & $1.33(0.71-2.51)$ & $1.38(0.73-2.61)$ \\
\hline $13.50-21.85$ (reference) & 1.0 & 1.0 & 1.0 & 1.0 & 1.0 \\
\hline
\end{tabular}

Adjusted for age, education, occupation, body mass index, alcohol consumption, smoking, and respective reason for retirement (cardiovascular diseases, musculoskeletal disorders, mental disorders, or other chronic diseases).

*Cardiovascular diseases include coronary heart disease, cardiac insufficiency, hypertension, claudication, and stroke.

†Musculoskeletal disorders include back problems and osteoarthritis.

$\ddagger$ Mental disorders include those diagnosed by doctor or severe psychic illnesses that required hospitalisation.

§Other reasons include respiratory, metabolic, dermatological, digestive tract, eye and ear diseases, injuries, cancers, malformations, and non-classifiable diseases.

\section{DISCUSSION}

The novel finding of this prospective population based study is a strong association between poor cardiorespiratory fitness and an increased risk of disability pension. A low $\mathrm{VO}_{2 \max }$ and a short duration of exercise test were associated with an increased risk of disability pension, especially due to cardiovascular diseases, but also due to musculoskeletal disorders, when other potential risk factors were controlled for.

Physical activity and cardiovascular fitness have been shown to have favourable effects on cardiovascular and musculoskeletal systems. ${ }^{13} 161737$ There is epidemiological evidence showing that regular physical activity and good cardiorespiratory fitness are effective in the prevention of cardiovascular diseases and premature mortality. ${ }^{18} 2038-40$ In the same population study of middle-aged Finnish men we have previously found that good cardiorespiratory fitness is associated with a reduced risk of coronary heart disease, ${ }^{15}$ and with reduced overall, cardiovascular, and non-cardiovascular mortality. ${ }^{18}$

Physical exercise promotes musculoskeletal health by preventing osteoporosis, ${ }^{22}$ and with moderate dosing probably also low back and neck-shoulder disorders ${ }^{16} 192425$ as well as osteoarthritis of non-injured joints. ${ }^{24} 2627$ In addition to prevention of musculoskeletal diseases, physical activity appears to be favourable in the treatment of osteoporosis, ${ }^{22}$ chronic low back disorders, ${ }^{24} 41$ and osteoarthritis. ${ }^{14} 242742$

There is much less evidence of the primary and secondary prevention of mental disorders by physical activity and physical fitness. Two earlier studies showed a reduction in symptoms of depression attributable to both aerobic and resistance exercise. ${ }^{30} 43$

Thus, there exists relatively good evidence of the health effects of physical exercise and cardiorespiratory fitness with respect to cardiovascular and some musculoskeletal disorders. However, disability pension has multifactorial aetiology and a preceding disease explains only a part of it. ${ }^{6-9}$ There are few earlier studies on the role of cardiorespiratory fitness or physical activity in the prevention of work disability or in maintaining work ability. In a Finnish longitudinal study, physical exercise predicted a good work ability index. ${ }^{44}$ In the same study cardiorespiratory capacity correlated with work ability in subjects with no musculoskeletal disorders, but not in those who had musculoskeletal or cardiovascular disease. ${ }^{45}$
During the past decade there has been a considerable amount of effort in occupational health services to promote work ability by carrying out different exercise intervention programmes. At the moment there is a strong evidence of their positive effects on physical activity ${ }^{46}{ }^{47}$ and musculoskeletal disorders ${ }^{48}{ }^{49}$ provided that individual support is included in these programmes. ${ }^{50} 51$

The strengths of the present study include the representative population based sample of men at the age of high occurrence of disability pension and the long follow up time of the study. Cardiorespiratory fitness, an objective marker of physical activity, was assessed accurately at baseline by a direct measurement of $\mathrm{VO}_{2 \max }$ during a maximal symptom limited exercise stress test on a cycle ergometer, a method that is widely used in clinical practise. However, the exercise test was performed only once and it is possible that cardiorespiratory fitness may have changed during follow up. We had reliable data on disability pension decisions, since the pensions were ascertained using pension registers that cover all Finnish citizens. Extensive measurements of risk factors at baseline enabled us to control for the potential confounders comprehensively. Although we carefully adjusted for a number of possible confounders, there may still be some residual confounding. It is, however, unlikely that this would explain the observed relations. In the present study, only men were examined and these findings cannot be directly generalised to women.

Over $80 \%$ of the middle-aged men in the present cohort had at least one chronic disease at baseline, which provides one explanation for the high incidence of disability pension during follow up. Previous studies have shown that the prevalence of chronic diseases in eastern Finland is higher than in other parts of Finland ${ }^{52}$; on the other hand the incidence and mortality from coronary heart disease in Finland is among the highest in the world. ${ }^{53}$ The high prevalence of chronic diseases and the high incidence of disability pension during follow up can also be explained by low educational level and heavy occupations in the present cohort. The incidence of disability pension during the follow up period in the present study is of about the same grade as in Finland generally. ${ }^{1}$ It is, however, difficult to make international comparisons because the age of the subjects and the length of follow up varies between the studies. ${ }^{13} 54$ 
Early retiring is a significant social problem in western countries. Methods to prevent early retiring and to maintain working ability are needed. More prospective studies are needed to investigate the effect of physical activity, cardiorespiratory fitness, and exercise intervention programmes in the prevention of early retiring. In the present study even moderate levels of physical fitness were associated with a decreased risk of disability pension, especially due to cardiovascular diseases. Consequently, more attention should be paid to improvement of cardiorespiratory fitness by physically active lifestyle in the working age population.

\section{ACKNOWLEDGEMENTS}

We thank the staff of the Research Institute of Public Health, University of Kuopio, and Kuopio Research Institute of Exercise Medicine for data collection in the KIHD study. This study was supported by The Social Insurance Institution of Finland. The KIHD study was supported by grants from the Academy of Finland, the Ministry of Education of Finland, the city of Kuopio, and the National Heart, Lung and Blood Institute of the USA. Dr TA Lakka was supported by grants from the Academy of Finland, the Yrjö Jahnsson Foundation, the University of Kuopio, and the Paavo Nurmi Foundation.

\section{Authors' affiliations}

M Karpansalo, Research Institute of Public Health, University of Kuopio, Finland

P Manninen, J Kauhanen, Department of Public Health and General

Practice, University of Kuopio

R Rauramaa, Kuopio Research Institute of Exercise Medicine

J T Salonen, Inner Savo Health Centre, Suonenjoki, Finland

T A Lakka, Pennington Biomedical Research Center, Lovisiana State University, Baton Rouge, USA (TAL)

\section{REFERENCES}

1 Hytti H. Early retirement-the Finnish model, Helsinki Social Insurance Institution, Finland, Studies in social security and health. 1998;32:164-71.

2 Kaprio J, Sarna S, Fogelholm M et al. Total and occupationally active life expectancies in relation to social class and marital status in men classified as health at 20 in Finland. J Epidemiol Community Health 1996;50:653-60.

3 Månsson N, Eriksson K, Israelsson B, et al. Body mass index and disability pension in middle-aged men-non-linear relations. Int J Epidemiol 1996;25:80-5.

4 Upmark M, Lundberg I, Sadigh J, et al. Psychosocial characteristics in young men as predictors of early disability pension with a psychiatric diagnosis. Soc Psychiatr Epidemiol 1999;34:533-40.

5 Yelin E, Henke C, Epstein W. Work disability among persons with musculoskeletal conditions. Arthritis Rheum 1986;29:1322-33.

6 Milhous R, Haugh L, Frymoyer J, et al. Determinants of vocational disability in patients with low back pain. Arch Phys Med Rehabil 1989;70:589-93.

7 Bonzani P, Millender L, Keelan B, et al. Factors prolonging disability in workrelated cumulative trauma disorders. J Hand Surg 1997;22:30-4.

8 Aronoff G, Feldman J, Campion T. Management of chronic pain and control of long-term disability. Occup Med 2000;15:755-70.

9 Mittag O, Kolenda K, Nordman K, et al. Return to work after myocardial infarction/coronary artery bypass grafting: patients' and physicians' initial viewpoints and outcome 12 months later. Soc Sci Med 2001;52:1441-50.

10 Appelberg K, Romanov K, Heikkila K, et al. Interpersonal conflict as a predictor of work disability: a follow-up study of 15,348 Finnish employees. J Psychosom Res 1996;40:157-67.

11 Manninen P, Riihimäki $\mathrm{H}$, Heliövaara $M$, et al. Overweight, gender and knee osteoarthritis. Int J Obes Relat Metab Disord 1996;20:595-7.

12 Månsson N, Råstam L, Eriksson K, et al. Socioeconomic inequalities and disability pension in middle-aged men. Int J Epidemiol 1998;27:1019-26.

13 Biering-Sørensen F, Lund J, Høydalsmo O, et al. Risk indicators of disability pension. Danish Medical Bulletin 1999:46:258-62.

14 Berg M, Helakorpi S, Puska P. Finnish adults health behaviour. Spring 1993. Publications of the Social Insurance Institution 1993:B10.

15 Lakka T, Venäläinen J, Rauramaa R, et al. Relation of leisure-time physical activity and cardiorespiratory fitness to the risk of acute myocardial infarction in men. N Engl J Med 1994;330:1549-54.

16 Vuori I. Exercise and physical health: musculoskeletal health and functional capabilities. Res Q Exerc Sport 1995;66:276-85.

17 Fletcher G, Balady G, Blair S, et al. Statement on exercise: benefits and recommendations for physical activity programs for all Americans. Circulation 1996;94:857-62

18 Laukkanen J, Lakka T, Rauramaa R, et al. Cardiovascular fitness as a predictor of mortality in men. Arch Intern Med 2001;161:825-31.
19 Linton S, van Tulder M. Preventive interventions for back and neck pain problems: what is the evidence? Spine 2001;26:778-87.

20 Blair S, Kampert J, Kohl HI, et al. Influences of cardiorespiratory fitness and other precursors on cardiovascular disease and all-cause mortality in men and women. JAMA 1996;276:205-10.

21 Sesso H, Paffenbarger RJ, Lee I. Physical activity and coronary heart disease in men: The Harvard Alumni Health Study. Circulation 2000;102:981-6.

22 Lee I. Physical activity, fitness, and cancer, Champaign, IL, Human Kinetics Publishers, 1994.

23 Kujala U, Kaprio J, Kannus P, et al. Physical activity and osteoporotic hip fracture risk in men. Arch Intern Med 2000;160:705-8.

24 Vuori I. Dose-response of physical activity and low back pain, osteoarthritis and osteoporosis. Med Sci Sports 2001;33:551-86.

25 Hildebrandt V, Bongers $\mathrm{P}$, Dul J, et al. Review: The relationship between leisure time, physical activities and musculoskeletal symptoms and disability in worker populations. Int Arch Occup Environ Health 2000;73:507-18

26 Buckwalter J, Lane NE. Athletics and osteoarthritis. Am J Sports Med 1997;25:873-81.

27 Lequesne M, Dang N, Lane N. Sport practice and osteoarthritis of the limbs. Review. Osteoarthritis Cartil 1997;5:75-86.

28 Arokoski J, Jurvelin J, Väätäinen U, et al. Normal and pathological adaptations of articular cartilage to joint loading. Review. Scand J Med Sci Sports 2000; 10:186-98.

29 Manninen P, Riihimäki H, Heliövaara $M$, et al. Physical exercise and risk of severe knee osteoarthritis requiring arthroplasty. Rheumatology 2001;40:432-7.

30 Dunn AL, Trivedi MH, O'Neal H. Physical activity dose-response effects on outcomes of depression and anxiety. Med Sci Sports Exerc 2001;33:587-97.

31 Salonen J. Is there a continuing need for longitudinal epidemiologic research? The Kuopio Ischaemic Heart Disease Risk Factor Study. Ann Clin Res 1988;20:46-50.

32 Lynch J, Kaplan G, Cohen R, et al. Childhood and adult socioeconomic status as predictors of mortality in Finland. Lancet 1994;26:524-7.

33 Tiihonen J, Pesonen U, Kauhanen J, et al. CYP2A6 genotype and smoking Mol Psychiatry 2000;5:347-48.

34 Lakka H, Lakka T, Tuomilehto J, et al. Hyperinsulinemia and the risk of cardiovascular death and acute coronary and cerebrovascular events in men. Arch Intern Med 2000;160:1160-8.

35 Kauhanen J, Julkunen J, Salonen J. Coping with inner feelings and stress: heavy alcohol use in the context of alexithymia. Behav Med 1992;18:121-6.

36 Rothman K, Greenland S. Modern epidemiology, 2nd ed. USA: LippincottRaven, 1998.

37 Pate R, Heath G, Dowda M, et al. Associations between physical activity and other health behaviors in a representative sample of US adolescents. Am J Public Health 1996;86:1577-81.

38 Morris C, Froelicher V. Cardiovascular benefits of physical activity. Herz $1991 \cdot 16: 222-36$

39 Smith SJ, Blair S, Criqui $M$, et al. Preventing heart attack and death in patients with coronary disease. Circulation 1995;92:2-4.

40 Lakka T, Laukkanen J, Rauramaa R, et al. Cardiorespiratory fitness and the progression of carotid atherosclerosis in middle-aged men. Ann Intern Med 2001; 134:12-20.

41 van Tulder M, Malmivaara A, Esmail RBK. Exercise therapy for low back pain: a systematic review within the framework of the Cochrane collaboration back review group. Spine 2000;25:2784-96.

42 Puntila $\mathrm{E}$, Kröger H, Lakka T, et al. Physical activity in adolescence and bone density in peri- and postmenopausal women: a population-based study. Bone 1997;21:363-7.

43 Lobstein D, Mosbacher B, Ismail A. Depression as a powerful discriminator between physically active and sedentary middle-aged men. J Psychosom Res 1983:27:69-76.

44 Tuomi K, Eskelinen L, Toikkanen J, et al. Work load and individual factors affecting work ability among aging municipal employees. Scand J Work Environ Health 1991;17(suppl 1):128-34.

45 Nygård C, Eskelinen L, Suvanto S, et al. Associations between functional capacity and work ability among elderly municipal employees. Scand J Work Environ Health 1991;17(suppl 1):122-7.

46 Kriska A, Bayles C, Cauley J, et al. A randomized exercise trial in older women: increased activity over two years and the factors associated with compliance. Med Sci Sports Exerc 1986;18:557-62.

47 King A, Haskell W, Youg D, et al. Long-term effects of varying intensities and formats of physical activity on participation rates, fitness, and lipoproteins in men and women aged 50 to 65 years. Circulation 1995;91:2596-604.

48 Donchin M, Woolf O, Kaplan L, et al. Secondary prevention of low-back pain. A clinical trial. Spine 1990;15:1317-20.

49 Gundewall B, Liljeqvist M, Hansson T. Primary prevention of back symptoms and absence from work. Spine 1993;18:587-94.

50 Ostwald S. Changing employees' dietary and exercise practices: an experimental study in a small company. J Occup Med 1989:31:90-6.

51 Cardinal B, Sachs M. Prospective analysis of stage-of-exercise movement following mail-delivered, self-instructional exercise packets. Am J Health Promotion 1995:9:430-2.

52 Salomaa V, Arstila M, Kaarsalo $E$, et al. Trends in the incidence of and mortality from coronary heart disease in Finland, 1983-1988. Am J Epidemio 1992;136:303-15.

53 Uemura K, Pisa Z. Trends in cardiovascular disease mortality in industrialized countries since 1950. World Health Stat $Q$ 1988:41:155-78.

54 Månsson N, Merlo J. The relation between self-rated health, socioeconomic status, body mass index and disability pension among middlle-aged men. Eur J Epidemiol 2001;17:65-9. 